\title{
The Material Role of Digital Media in Connecting With, Within, and Beyond Museums
}

\begin{abstract}
The connective potentials of digital media have been positioned as a key part of a contemporary museum visitor experience. Using a sociology of translation, we construct a network of visitor experiences using data from a digital media engagement project at a large and multi-sited museum in the United Kingdom. These experiences relate to (dis)connections with the museum, museum objects, and other visitors. Through this analysis we disclose the often contradictory roles of the non-human, including and going beyond the digital, as contributors to the success and failure of attempts to change museum visitor experiences through engagement activities rooted in narratives of participation and connectivity.
\end{abstract}

\section{Museums, visitor engagement, and digital media}

In museums today there is a focus on the demographic of the visitor and a desire to reconstruct their encounter in terms of experiences of dialogue, conversation and democracy (Vergo 1989, Bagnall 1996, Staniszewski 2000, Brandon 2007, Kidd 2009, Kidd 2011). The intention of museums has been to make collections more relevant and accessible, allowing visitors to feel more engaged and to have a greater sense of ownership, connection and participation (Srinivasan et. al., 2009). As Kidd (2011, 2014) has shown, many museums have looked to different forms of digital media to facilitate these types of exchanges. However, as Kidd (2014) continues, there have been mixed outcomes, and in particular, she highlights the struggles over authorship that this can entail; challenging whether it signals a more active and vibrant democratic participation.

Additionally, there is an on-going tension between modes of interpretation in museums, with 
their participatory agendas, and the perception of some critics that there is a lack of attention to, and focus upon, the object. Many critics have derided what they regard as the increasingly media and spectacle-dominated exhibitions, with their adoption of digital technologies, conspicuous consumption, and an emphasis on novelty (Message, 2006). Fleming (2005) has even gone so far as to argue that a consequence of this is that objects can be positioned as almost irrelevant to the museum experience. This is a position which denies objects the ability to have any say, unless humans are involved. Alternatively, it has been claimed that museums are increasingly popular because of the materiality of their objects (Bagnall and Rowland 2010). Museum objects are said to function as active producers of meaning; allowing visitors to connect to memories and biographies, and to perform forms of reminiscence (Bagnall 1996, Bagnall 2003). It is this question of the material role of the non-human in museums that is our focus in this paper.

A national museum, with five branches across the UK, the Imperial War Museums' (IWM) remit is to enable and encourage the study and understanding of the history of modern war and wartime experience (IWM, 2015). The IWM's intention was to apply social media models to the interpretation of selected collections at two of its branches, IWM London and IWM North. The aim of the project was to provide new frameworks for visitor engagement and social interpretation; that is the representation of, discussions about, and the sharing of, museum objects by visitors. To do this the IWM and its technical partners installed comment and information kiosks and QR $\operatorname{codes}^{1}$ next to exhibits, developed a mobile app — Scan and Share - and added social interpretation functions to its main website. In respect of this, our research questions were:

\footnotetext{
${ }^{1} \mathrm{~A}$ QR code (quick response code) is form of a machine-readable optical label that contains information about the item to which it is attached to or associated with. Codes are usually read by a scanner and in recent years this function has been incorporated in smartphones via a range of apps that access a devices camera.
} 
- How, if at all, are visitor relations with museums, museum objects, and other visitors transformed through the presence of digital media?

- What role, if any, do digital media play in (dis)connectedness in the museum experience?

While it has been argued that 'technology is a tool for museums to achieve certain goals, a tool to support experiential infrastructure' (Smith Bautista 2014: 228), we see digital media as more than a tool subject to human agency. We demonstrate how digital media is implicated in such arrangements. When considered in this way, digital media, and the other non-human actors it might engage with (such as lighting, WiFi, and museum collections) become an integral consideration in changing museum experiences. The role of increasing visitor engagement and connection is delegated (Latour 1992) to the digital by museum staff.

In the next section we refer to research regarding the role of connection building as part of museum practice. We also introduce a sociology of translation approach, from Actor-Network Theory (ANT), which is helpful for thinking about how connection may, or may not, operate when we go beyond a focus upon human agency.

\section{Assembling connectivity and visitor engagement with museums}

A fundamental aspect of museum practice is to connect with a diversity of visitors and digital media is seen as an enabler in this respect (Dyson, Andrews et al. 1995, Srinivasan et. al., 2009; Smith Bautista 2014). Such a position draws on the rise of general interest in the participatory cultures enabled by the web, particularly since the evolution of 'Web 2.0' (Brandon 2007, Jenkins 2008; Burgess and Green 2009; Jarrett 2010; Lange 2012). Yet, 
connection and participation are not neutral. What it means to connect and participate with museums is imbued with power and politics. Visitors construct museums as populated by experts, educators, and purveyors of truth; they are seen as places to be trusted, where the visitor believes they will find some objective sense of the world (Bagnall 1996, Goulding 2000). Underpinning this is the idea that the museum is a place of formal and informal learning (Falk and Dierking 2000, Leinhardt et al. 2011), or a form of 'educative leisure' (Hanquinet and Savage, 2012: 42).

Museum staff may exercise a high degree of power over how a visitor experiences a museum, and how connection is configured. For example, preserving coherence throughout a visit can be seen as a problem that needs to be solved, where the need to deal with stragglers and deviation from that visit is curated by museum staff (Tolmie et al. 2014). Although research on visitor engagement with museums recognises the importance of allowing for and even enabling a malleable, flexible experience, the focus is still on maintaining an optimal level of user connection. However, we know that more generally, we cannot engage with digital media that seek to connect us, without having opportunities to disconnect (Light 2014, Light and Cassidy 2014). Importantly, Light (2014) demonstrates that disconnection with digital media is not merely about resistance or maintaining privacy; it may also concern adding value to our experiences.

We cannot assume a social, it is something that needs to be assembled (Latour 2005). By this we mean our ways of life are put together in particular ways for particular reasons. In this case, to attempt to configure the user, museum staff have to set up digital media based arrangements with an expectation that they will be used in ways that they have predetermined for visitors. However, we cannot assume that such a set of associations will form in the way 
museum staff expects them to. We know that users are adept at both appropriating technology and not using it (Akrich 1992, Oudshoorn and Pinch 2005, Light 2014).

In this paper we use a sociology of translation approach (Callon 1986) as a way of understanding the trajectory of a set of arrangements, and by highlighting the agency of human and non-human actors. Non-human actors in this context include, for example, $\mathrm{WiFi}$, mobile phones, QR codes, lighting, walls, and museum objects. This approach takes us beyond a tool view of the digital non-human in museums, to one which aims to describe how human and non-human actors set up a problem area, attempt to persuade others to share a similar view, and seek to have them act to further generate support for the problem area as they see it. Accounts of this type detail the processes of translation that occur amongst actors. Callon proposes four moments of translation, which can assist in understanding such a state of affairs:

- Problematisation - the rendering of a situation as a problem that involves the interdefinition of actors in such as way that an actor becomes indispensible - an obligatory passage point - actors are told this is the solution. For example, a museum may seek to present successful visitor engagement of a particular type as most fruitfully secured via the deployment of digital media.

- Interessement - the actions by which something or someone attempts to stabilise the definition of other actors in relation to problematisation - actors become interested in the solution. Various actors may engage here to strengthen associations and support network formation and development. For example, the use of already existing symbolic, yet material, devices such as liking/sharing functions associated with social media can be pressed into service in a museum context to reinforce the use of a set of arrangements.

- Enrolment - the process of negotiation that seeks to have actors persuaded to act out 
Light, B., Bagnall, G., Crawford, G. and Gosling, V. The Material Role of Digital Media in Connecting With, Within, and Beyond Museums, Convergence, Pre-publication Version.

the role that is being set for them in relation to the problem - actors engage with the solution. For example, visitors may be convinced by the problem situation and its interessement techniques to engage on the terms offered by a set of associations as prefigured by museum staff.

- Mobilisation - whereby actors are moved to speak on behalf of the problem - actors champion the solution. For example, visitors maybe so positively convinced by engagement arrangements that they seek to enroll others in their museum experience and/or advocate for others to generate their own experiences too. Effectively, visitors 'sell' the promise of digital media based engagement to others on behalf of the museum.

Furthermore, ANT requires a focus upon mediators rather than intermediaries (Latour 2005). Mediators are human and non-human actors that transform a set of associations, whereas intermediaries merely pass something along a network unchanged. For example, WiFi not working in a museum space may mean that a digital engagement attempt may not work. Here WiFi acts to change the situation as pre-figured. Where it works, one might see WiFi as an intermediary, a background actor that merely passes the visitor to an interface that then mediates their experience. This attention to points of mediation allows for an understanding of action and inaction. Moments of translation should not be thought of in a linear relationship and, the achievement of one moment might not lead to the other. As we will show through our case study, the process may destablise via dissidence, betrayals, and the emergence of controversies. Such moments can co-exist as associations are attempted in different ways by different actors. For these reasons, ANT, and more specifically, a translation approach to understanding provide a a valuable way to interrogate the complexities and contradictions of visitor engagement and connection with digital media in a museum context. This position offers scope to consider a broad range of actors and associations, and to 
demonstrate the importance of their contribution to museum experiences.

For ease of interpretation we have not strictly relied upon the vocabulary of ANT throughout our analysis. Rather, we have introduced a sociology of translation, and its moments of translation as a frame of reference to guide our interpretation and analysis of our data. In deploying this approach, we add to ANT informed work on museums that highlights interactions among museum objects, visitors and staff (Bennet 2005) and museum professionals, objects, the public and information technology (Kéfi and Pallud 2011). Our building upon this work occurs through the introduction of other actors and by examining the success and failures of changes.

\section{Method}

This case study draws from a large multi-method study based upon observation of the use of museum space, walking interviews with museum visitors, interviews with museum staff, a survey of museum visitors, focus groups with visitors, textual analysis of visitor comments made with digital media, and an analysis of the interfaces and functions of said digital media. For the purposes of this paper we draw on data from our observational work, interviews, focus groups, and the analysis of visitor comments.

Before and after the installation of the digital media, researchers in IWM London and IWM North spent a number of days in the museums, familiarising themselves with the exhibitions, the digital media (both the new kiosks/QR codes and those already in place), and the museum layout. This enabled us to begin to make sense of visitor activity and movement. We made notes about what we saw and heard as visitors interacted and engaged with the museum. This data was used to develop our interview and focus group guides. 
Prior to the implementation of the digital media, the team also conducted 20 semi-structured accompanied walking interviews with visitors and visitor groups - 10 in each location. Once the various elements of the digital media had been fully implemented across both sites, we conducted a further 20 semi-structured accompanied walking interviews — again 10 in each location. A recruitment guide was devised for both the pre- and post-implementation interviews that enabled us to select a cross-section of different visitor types (Falk 2000), which were reflective of the IWM visitor profile, and a range of socio-demographic factors. We collected a range of demographic data from the participants and our interview guides enabled us to observe, ask questions about, and capture rich experiences of museum visits before and after the implementation of the project. We were also able to explore the wider cultural and museum-visiting practices of the participants, their current use of and perspectives on digital and social media, and their thoughts on the role and risks of social interpretation. The walking interviews also afforded opportunities to discuss the functions and interfaces of the kiosks, apps, and QR codes in situ. The accompanied interviews were between 45 minutes and 60 minutes. Towards the end of the project we also conducted semistructured interviews with five Visitor Services Assistants at IWM London, and five gallerybased Security Officers at IWM North. Consequently, through these interviews we were able to gather staff perspectives on the degree to which visitors noticed and engaged with the digital media in the galleries, and the types of interaction that took place. These interviews also shed light on the extent to which staff had interacted with the visitors about the digital media, and if so what form that interaction had taken. Finally, we were able to gather staff opinion on the digital media, and their ideas on how, in the light of their observations, it might be improved. 
After the implementation of the project, we conducted two semi-structured focus group interviews with a cross section of recent visitors to IWM London and IWM North. Each focus group had seven participants and lasted approximately 90 minutes. The focus group interview guides and stimulus material that we developed, such as images of the kiosks and QR codes in situ, a selection of comments from the kiosks, and images of the various interfaces, enabled us to gather group opinion on the various features of the project. The discussions were helpful for understanding how this form of collecting and interpretation might be undertaken through other social media, and in other arts and cultural contexts. The focus group participants were encouraged to try out the mobile technologies during the focus group. They were asked to reflect on them as they interacted with them, and to discuss them with the others present. This allowed us to understand the use of the Scan and Share app, not just from the perspective of an individual's use of a specific form of digital media, but also how this might be embedded in the interactions of everyday life, and particularly in participants' engagement and interaction with museums and the arts and culture sector. Findings from the interviews and focus groups were captured through written notes, and were audio recorded to assist with the analysis process, the data from them was coded and subjected to thematic analysis.

The project team added five questions to a roll out of the IWM monthly visitor survey. The questions focused on the comment kiosks, as at the time of the survey this was the only element of the digital media that had been fully implemented. The questions explored the awareness and usage of the screens; what users enjoyed about them; suggested improvements, and reasons for non-engagement. In IWM London these questions were asked of 101 visitors who had been exposed to the comment kiosks. In IWM North, the questions were asked of 81 individuals who visited the museum after the comment kiosks went live. 
Textual and content analyses of visitor kiosk comments were also undertaken. We identified the extent of the commenting, the form and type of comment made (see Table 1), and the patterns of comments and commenting in the data. We also examined the extent, degree and form of moderation, and the type of comments that were moderated by visitors, the museum, or both. We noted the number of likes and dislikes for comments, and the type of comment these judgments were attached to.

Table 1. Categorisation of kiosk comments

\begin{tabular}{|c|c|c|}
\hline Category & Sub Category & Category Description \\
\hline \multirow{7}{*}{ 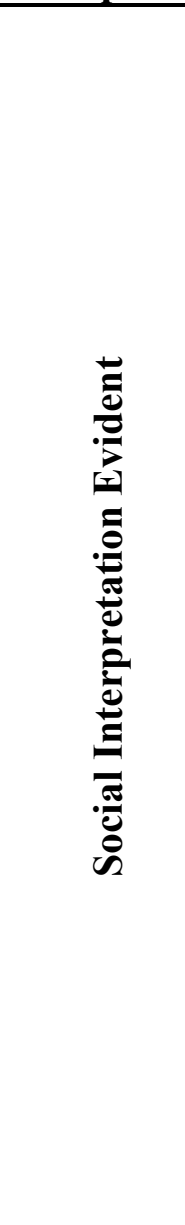 } & $\begin{array}{l}\text { Answer to } \\
\text { Prompt } \\
\text { Question }\end{array}$ & $\begin{array}{l}\text { A seemingly direct answer to the questions posed on the } \\
\text { comment screen. }\end{array}$ \\
\hline & $\begin{array}{l}\text { Interpretation of } \\
\text { Object in } \\
\text { Question }\end{array}$ & $\begin{array}{l}\text { A visitor has said something about the kiosk object in } \\
\text { front of them, but has not answered the prompt question. } \\
\text { They have engaged in their own interpretive experience. }\end{array}$ \\
\hline & $\begin{array}{l}\text { Interpretation of } \\
\text { Object } \\
\text { Elsewhere in } \\
\text { the Museum }\end{array}$ & $\begin{array}{l}\text { A visitor seems to have talked about an object or idea } \\
\text { from elsewhere in the museum. }\end{array}$ \\
\hline & $\begin{array}{l}\text { Question Posed } \\
\text { by Visitor to the } \\
\text { museum }\end{array}$ & $\begin{array}{l}\text { A visitor has asked the museum a question - they are } \\
\text { usually asking for more information/clarity regarding an } \\
\text { object. }\end{array}$ \\
\hline & $\begin{array}{l}\text { Positive } \\
\text { Comment about } \\
\text { IWM }\end{array}$ & $\begin{array}{l}\text { Visitor being positive about the museum overall, or the } \\
\text { exhibition they are in. }\end{array}$ \\
\hline & $\begin{array}{l}\text { Negative } \\
\text { Comment about } \\
\text { IWM }\end{array}$ & $\begin{array}{l}\text { Visitor being negative about the museum - usually } \\
\text { someone commenting that the museum is boring. }\end{array}$ \\
\hline & $\begin{array}{l}\text { Possible } \\
\text { Exchange }\end{array}$ & $\begin{array}{l}\text { Due to the mode of presentation of visitor comment data, } \\
\text { it was sometimes difficult to highlight dialogue that } \\
\text { happened amongst visitors but some responses seemed to } \\
\text { be responding to other comments or were a specific } \\
\text { attempt at networking in, and beyond, the museum space- } \\
\text { e.g. sharing of blackberry messenger details. }\end{array}$ \\
\hline 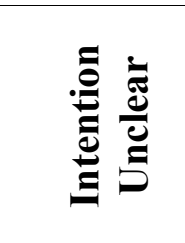 & $\begin{array}{l}\text { Intention } \\
\text { Unclear }\end{array}$ & $\begin{array}{l}\text { It was impossible to determine if some comments (e.g. } \\
\text { Awesome!) were a response to a prompt, a response to an } \\
\text { object, a reply to someone else or trolling. These } \\
\text { comments were coded unclear as a sub category and } \\
\text { category group. }\end{array}$ \\
\hline$\underline{\Xi}$ & $\begin{array}{l}\text { Only Name } \\
\text { Entered }\end{array}$ & No comment made, only a name has been entered. \\
\hline$\stackrel{\mathscr{e}}{\mathrm{g}}$ & $\begin{array}{l}\text { Spam and } \\
\text { Trolling }\end{array}$ & $\begin{array}{l}\text { Posts such as xxklfgasldfja, that had no meaning in the SI } \\
\text { project or a more general museum context }\end{array}$ \\
\hline
\end{tabular}




\section{Introducing digital media for visitor led social interpretation at the Imperial War}

\section{Museums}

The project deployed common features associated with social media such as liking, commenting, sharing, and collecting. The aspiration of the project team was to create a service that encouraged visitors to engage with IWM's collections through several forms of digital interaction and participation both in and out of the gallery. The project team sought to situate a good visitor experience as involving engagement with digital media. Digital engagement was seen as the option to improve the situation. Not only did this decision work with engagement narratives associated with contemporary museum practice, it aligned with those concerned with the demonstration of value for money of public arts and cultural organisations in the UK. In doing this, staff believed the project would demonstrate visitor engagement, as it generated usage data that could be used for evaluation purposes. This in turn would allow the museum to participate in other networks with evidence to favourably influence those in the area of funding policy for arts and culture in the UK. That is, IWM would be able to persuade others to speak for its visitor engagement practices where digital media was concerned, and ultimately its value as a public institution that was activity aligned with the UK's politics and policy related to public museums.

\section{Encouraging Social Interpretation Through the Introduction of Comment Kiosks}

IWM and its technical partners developed and installed six comment and information kiosks, each containing an interactive touch screen, in the A Family in Wartime temporary exhibition in IWM London. These were situated amongst a range of exhibits thought to be provocative by museum staff. Exhibits included were objects such as an infant's anti-gas helmet and an 

Connecting With, Within, and Beyond Museums, Convergence, Pre-publication Version.

evacuee label. The staffs' idea that these objects were provocative to visitors was integral in enabling them to act as effective mediators of the museum experience by engendering social interpretation and interaction. At IWM North similar comment kiosks, with slightly larger screens, were installed next to four large objects in the main exhibition hall. These included a tank, a fire tender, a field gun, and Baghdad, 5 March 2007, Jeremy Deller's installation featuring the wreckage of a car damaged by bombing. The comment kiosks invited visitors to offer a social interpretation in response to a prompt question posed by the museum. The kiosks in IWM London and IWM North differed in layout and functionality. The kiosks in IWM London had a dual voice interface design, involving two screens - one a digital information label projecting the museum voice and the other a comment screen that invited the visitor to make their own comment. In IWM North the kiosks had only one screen that invited the visitor to comment. During the study approximately 5 per cent of visitors left some kind of comment. 12,313 comments were made at IWM London and 7,817 at IWM North 20,130 comments in total. The distribution of the kinds of comments made (based on the categories generated by analysis (Table 1) is shown in 
Light, B., Bagnall, G., Crawford, G. and Gosling, V. The Material Role of Digital Media in Connecting With, Within, and Beyond Museums, Convergence, Pre-publication Version.

Table 2. Of those comments made, 43 per cent had some form of interpretation evident across the museum sites (Figure 1). Whilst we recognize that spam and trolling may have value and be helpful to digital interaction, in the case of this project it did not, because it did not add to the social interpretation. The trolling and spam bore no direct relevance to our research when we reviewed it, and we have therefore excluded it from further analysis. 
Light, B., Bagnall, G., Crawford, G. and Gosling, V. The Material Role of Digital Media in Connecting With, Within, and Beyond Museums, Convergence, Pre-publication Version.

Table 2. Extent of commenting by category type and location

\begin{tabular}{|lrrr|}
\hline & $\begin{array}{r}\text { IWM } \\
\text { North }\end{array}$ & $\begin{array}{r}\text { IWM } \\
\text { London }\end{array}$ & $\begin{array}{r}\text { Grand } \\
\text { Total }\end{array}$ \\
\hline Answer to Prompt Question & 1421 & 1130 & 2551 \\
Interpretation of Object in Question & 1790 & 2050 & 3840 \\
Interpretation of Object Elsewhere in the & 92 & 433 & 525 \\
Museum & & & \\
Question Posed by Visitor to the Museum & 108 & 155 & 263 \\
Positive Comment about IWM & 302 & 834 & 1136 \\
Negative Comment about IWM & 20 & 57 & 77 \\
Possible Exchange & 74 & 170 & 244 \\
Intention Unclear & 1686 & 2065 & 3751 \\
Only Name Entered & 652 & 857 & 1509 \\
Spam and Trolling & 1672 & 4562 & 6234 \\
Grand Total & 7817 & 12313 & 20130 \\
\hline
\end{tabular}


Light, B., Bagnall, G., Crawford, G. and Gosling, V. The Material Role of Digital Media in Connecting With, Within, and Beyond Museums, Convergence, Pre-publication Version.

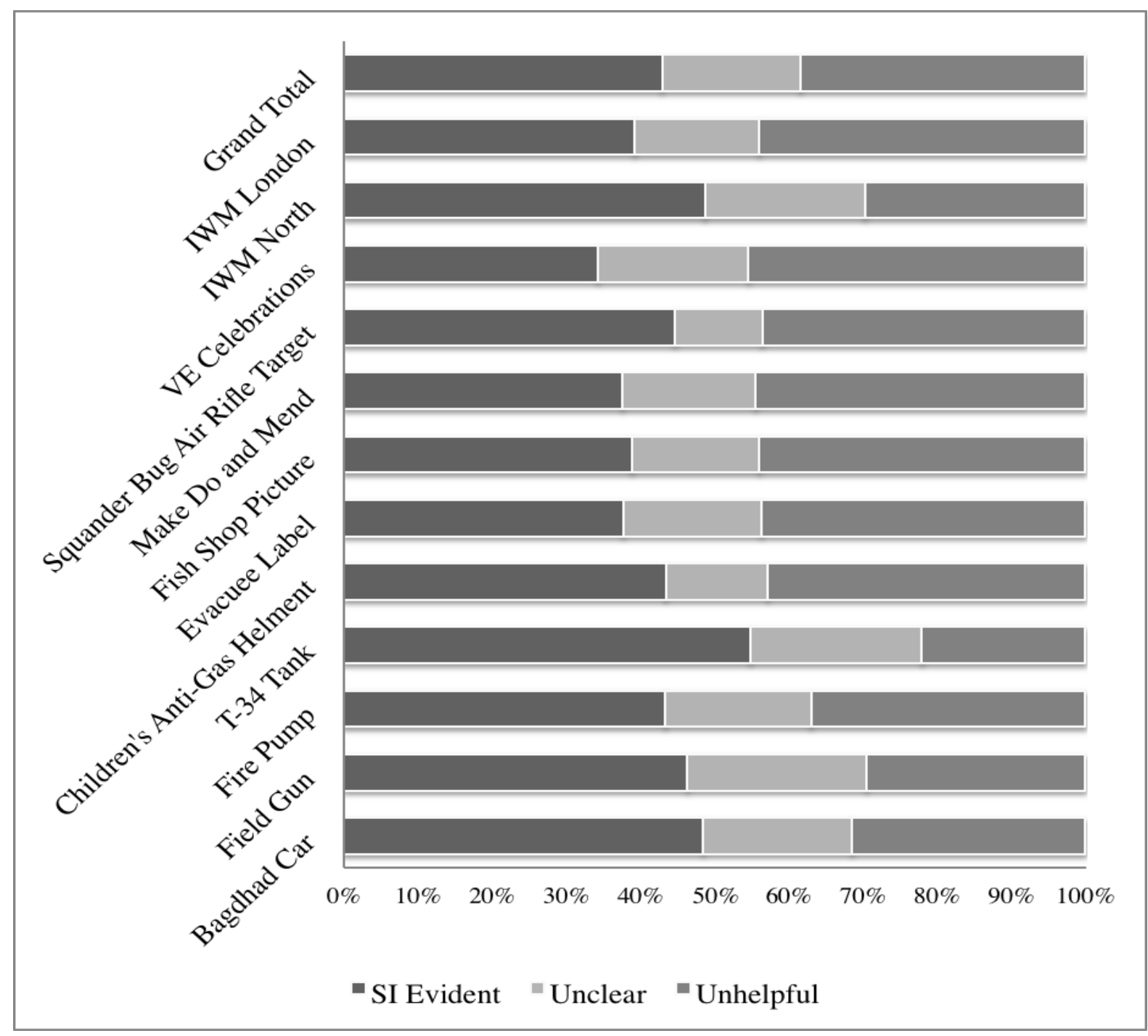

Figure 1. Forms of commenting via the kiosk by object

\section{The Role of the Kiosks in Connecting with the Museum.}

1136 (5.6 per cent) of comments made with the kiosks in IWM London and IWM North expressed a positive response to the museum and the experience it offered. Many of these comments were banal, for example: 'Great museum' or 'I love this exhibition.' However, some were more considered: 'I love the insight the Imperial War Museums gives you into the war and how hard it must have been for instance'. Although this sort of commentary was not the change in experience expected to occur, which aimed to encourage interpretation of the objects themselves, in most cases it expressed a genuine sentiment, and suggested that some 
visitors became connected with the museum. The kiosks also engaged some visitors with the museum by their existence as material objects of the museum space. We also observed many visitors approaching kiosks to find out what they were. The kiosks prompted a response that was neither about the object generally or a response to the prompt question positioned on the kiosk screen. For example, when asked about the purpose of the kiosks, a small number of visitors understood them as devices that called out for feedback and comments from them about the museum. The kiosks were likened to visitor comment cards. In such cases the overall experience of the museum worked with the kiosk and the visitor to change the experience in an unexpected way. This change was effected at the expense of other actors such as the object associated with the kiosk, or other objects nearby. Visitors did not engage with the kiosks on the museum's terms.

Some visitors felt that a greater presence of digital media helped to make the museum experience relevant for young people. Several interviewees were emphatic about the importance of children engaging with the historical information presented by the museum, and were inclined to be positive about anything that encouraged this, as one mother told us:

The more the better I think with you two [her children] isn't it? Because everywhere they do remember where we have been in the past, it's always the stuff they've done rather than what they've seen that's made it stand out to them

(F, 35-44, IWM North, walking interview).

Some participants were therefore happy for a change in the museum experience to occur for others. However, we also identified a tension here. While the value and relevance of digital media for children was acknowledged, there was an awareness from visitors at both locations that this could lead to inappropriate engagement with the kiosks. This inappropriate engagement was positioned as being off-putting for adults:

Yes. There's a lot of interactive screens which are very good but you tend to find that kids mess about with them and you don't use them for what they're meant to be used 
for...Although to get a kid interested in a museum it's a good idea, interactive, they need to be tactile don't they

(M, 25-34, IWM North, walking interview).

The Role of the Kiosks in Connecting with objects.

6391 (31.7 per cent) of kiosk comments were associated with the object in question. These comments suggested that the objects had increased a visitor's sense of connectedness to that object. For example, a visitor to IWM North, in response to the question 'How would you feel if you had to fire this gun?' placed on a comment kiosk next to a field gun, wrote: 'I would feel scared because I might shoot my own people'. These sorts of comments suggest that for some visitors, the invitation to offer their perspective through the kiosks encouraged them to relate to the collection in a more personal way. The making of comments means that these visitors could, but not necessarily, encourage others visitors to engage too. We noticed in the gallery spaces, how the presence of a visitor typing a comment at a kiosk, often led to someone walking over directly afterwards to take a look the kiosk themselves. In this way, the act of engaging with the kiosk also speaks to practices where, physically, visitors speak on behalf of the kiosks. According to the survey, 22 per cent of those engaging with the kiosks in IWM London were prompted to think more deeply about the exhibit by the comment kiosks, and at IWM North this was 9 per cent ${ }^{2}$. Further, some participants in the focus groups and walking interviews recognised that being able to engage in a discussion about particular objects - by reading as much as by commenting - might increase their sense of connectedness with those objects. This was especially the case if there was an opportunity to ask questions and have these answered by knowledgeable people. However, in general participants felt that the comment kiosks did not deliver a sufficient volume of relevant comments about objects to enable an engaging discussion or dialogue. Engagement did not occur on a wider scale for this particular set of arrangements. In addition, some interviewees expressed concern that the need

\footnotetext{
${ }^{2}$ Base: Used comment kiosks: IWM London $=55$, IWM North $=28$
} 
to focus on a screen might actually distract the visitor from looking closely at and thinking about the objects on display:

For example my son is ten years old he likes thumbs down, he likes all this but he doesn't sometimes recognise that things kill people. He is too young, for him this is cool so I think this is not a good way to show people this kind of thing, to show people that what you see now is not just cool kind of thing but something that kills people (M, 30-39, IWM North, focus group).

The kiosks were actors that might not only fail in their attempts at engagement, but they might also impact negatively on an experience in ways which would not occur if they had not existed. As indicated earlier, the kiosks deployed interface elements from social media. In the instance above, we see how the symbolism of the thumb, referencing the liking affordances of many social media platforms, materially shapes action by the 10 year old boy that is then perceived by his father as superficial.

The Role of the Kiosks in Connecting with other visitors.

The kiosks sought to generate connections among visitors, encouraging them to share perspectives and interpretations in parallel to, or in competition with, the interpretation offered by the museum. Changes during the course of the project meant that the kiosks were not linked with the app and website, as originally intended. Nonetheless, by commenting with the kiosks, it was possible to communicate with a wider group of visitors. The kiosks also sought to engage visitors by inviting them to reply to comments made by others as well as asking them to post their own. Some visitors felt that reading what others had to say helped them feel more connected with others. According to the visitor survey, 38 per cent of users in IWM London and 44 per cent in IWM North said that the main thing they enjoyed about the presence of the kiosks was reading other people's perspectives on the exhibit ${ }^{3}$. This suggests

\footnotetext{
${ }^{3}$ Base: Used comment kiosks: IWM London $=55$, IWM North $=28$
} 
that there is a desire amongst museum visitors to hear voices beside the museums'. However, there was minimal evidence that the comment kiosks facilitated an explicit dialogue amongst visitors, with only 1.2 per cent of comment contributions being categorised as displaying some form of attempt to engage. Where visitors left a relevant and considered comment on one of the screens, our interviews and focus group data suggested this was motivated at least partly by a desire to share their thoughts with fellow visitors. Many participants stated that they would be interested in hearing from fellow visitors via the kiosks - but only certain types. The most frequently cited types of people were visitors with personal experience of the period or events in question, especially if this was first hand. Interviewees suggested that these actors gave a greater degree of credibility and interest to comments. A smaller number said they would like to hear from people with expert knowledge of the subject, such as historians or archivists. One or two said they would be keen to read comments from ordinary visitors, provided these constituted interesting responses to an interesting question. However, several participants claimed to have little or no interest in hearing from other visitors, giving variations of the response: 'We don't care what other people think'. Some explicitly said that it was the voice of the museum they valued, not other visitors:

I come to a museum to learn - I want the experts to tell me about things (Focus Group: M, 35-44).

These participants said that they had no interest in sharing their own opinions, with several claiming that they were not 'the sort of person' who comments publicly on matters:

Focus Group: I'm generally not one to comment on things. I'd keep it to myself or comment to the person with me (F, 20-29).

Most focus group participants felt that the majority of the kiosk comments were uninteresting - based on what they had experienced in the galleries, or by reading a sample in the focus groups. This led our participants to question the rationale for the kiosk's existence. These 
visitors rejected the museum's position that digital media was engaging along with its deployment of provocative objects and social media functions such as liking and sharing. When talking about what would make for an engaging comment, participants did not seem to draw a strong distinction between statements from other visitors and statements from people speaking, as it were, 'on behalf of' the museum. For example, some in IWM London cited the War Stories exhibit, with its personal stories from soldiers returning from Afghanistan, as a desirable example of other voices. Although many visitors seem to welcome the idea of hearing from a wide range of sources, one of which may be ordinary visitors, for some what matters is the content and credibility of the material rather than the opportunity to form a digitally mediated connection with other visitors per se.

\section{Introducing $Q R$ Codes and an App to Engender Social Interpretation by Visitors}

IWM London placed QR codes next to six exhibits in A Family in Wartime, mostly small objects such as a dress made of parachute silk and a set of railway timetables. QR codes were also placed next to a significant proportion of the paintings in the Breakthrough Art gallery in IWM London. At IWM North, QR codes were placed next to nine objects in the main gallery, including a nuclear bomb, steelwork from the 9/11 World Trade Centre, and a child's gas mask. There were some differences in the design of the QR Codes in the various galleries. In A Family in Wartime, the codes were relatively small and embedded in the existing object description labels. By contrast, those in Breakthrough Art and at IWM North were larger and stood apart from object labels. These QR codes were also accompanied by a question that sought to engage visitors in social interpretation activity. An example question was: 'Would this poster make you want to join the army?' In some instances, these prompts mediated the visitor experience further, and sought to secure a successful engagement, by including directions as to where to locate the object. For example: 'Look to your right to see a piece of 
the Berlin Wall'. After scanning a QR code with their smartphone, the visitor would be directed to a mobile webpage where they would be presented with further information about the object.

In a further attempt at steering the visitor experience in particular ways, IWM and its technical partner developed a mobile app called Scan and Share. This app enabled visitors who scanned a QR code to access an object's story, comment on it, share stories of their own memories and experiences, and create and share their own museum collection with range of social media. The QR codes and app were put in place late in our study and thus we only had two months data generated by these in addition to our interviews and focus group work. 183 downloads of the app occurred during this time. In IWM London, the QR codes in Family in Wartime were scanned using either a generic QR code reader or the app 715 times, of these 523 were prior to the launch of the app. This is equivalent to 0.1 per cent of visitors to IWM London scanning a single code during this time. Additionally, there were 185 page views of the mobile web pages associated with the QR codes in Breakthrough Art for the period. There were 446 page views of the mobile web pages associated with the QR codes in IWM North, equivalent to 1 per cent of visitors to IWM North in this time. Most views of the object pages associated with the QR codes were unique views via different devices and did not lead to further exploration of other pages leading from the landing page. The process of engagement stalled at this point and the broader network of actors on the IWM website were not brought into action. As we will go on to describe, the app failed to have visitors communicate their museum experience to others.

(Not) Engaging Visitors with QR Codes and the App. 
There is little evidence that, during our study, the QR codes and app engaged visitors in forming connections with the museum, the objects in its collection or each other. A minority of participants in the walking interviews and focus groups, particularly students and parents, had felt that the ability to collect and share certain objects could be appealing in certain circumstances. If the object was one that the visitor had a special interest in, then the QR codes might offer a way to save a record of it, potentially to allow for further investigation outside the museum. A few interviewees were interested in the ability to capture objects with the app or QR code scanner because doing so would allow them to show others what they had seen. Participants in the walking interviews and focus groups instead identified six points of disruption with respect to the successful translation of the museum experience with the QR codes and app.

First, the QR codes were said to be too discreet, particularly in IWM London. The QR codes were said to have limited labeling and signage that did not always explicitly indicate a method of scanning for visitors. Although, most respondents in IWM London said they had noticed the QR codes, none had read the accompanying label or felt clear about what would happen if they scanned them. In these instances, signage and labeling were seen as material (missing) actors that did not succeed as devices that facilitated engagement.

Second, a significant proportion of visitors simply lacked the necessary devices, software or skills to respond to the invitations to translate their experience with the QR codes and the app (a smartphone with QR code reader, or an iPhone to download the app). Even visitors with smartphones had limited familiarity with QR codes. Most participants were aware of the existence of QR codes and understood that one was meant to scan them with a phone, but only two or three had ever done so before. This unfamiliarity discouraged visitors from 
exploring further after the QR codes attempted to engage them. This lack of engagement was especially the case for older visitors, a key demographic of IWM. Some participants also affirmed a very traditional, class-based view of what it means to experience a museum. As has been found in studies of other 'high culture' experiences, certain behaviours are expected (Crawford et. al. 2014 a, 2014b). In this respect several young people, not just older visitors, were very much against the use of mobile phones in a museum context as they were seen as distracting and detracting from an appropriate experience. As one participant stated 'museums are no place for mobile phones' (M, 18-25, IWM North walking interview). Therefore, while interest was generated, change did not occur, due to the sociotechnical abilities and views of visitors, and their device (non) ownership.

Third, several visitors expressed a concern about possible infrastructure challenges as actors destabilizing the process of engagement. These actors included a poor phone signal in the museum and the cost involved in using a mobile data plan to access the internet (especially for international visitors). Very few visitors we engaged with were aware that IWM London and IWM North offered free WiFi. This WiFi availability was signaled, in small print, on the back of the hard copy visitor guide. This guide was not automatically handed to every visitor upon entrance. The WiFi also presented itself to visitors if they scanned for it in-gallery using an appropriate device. The WiFi was seen to fail to act. Beyond these immediate issues raised, even where engagement began to occur, another gallery activity surfaced as a competing actor that destabalized the process. At IWM North, a variety of short films are regularly projected on to the main gallery walls. At this point the lights in the gallery are automatically dimmed and we noticed how the audience behavior patterns typically associated with cinema came into being; visitors would find somewhere to sit or stand, and the gallery went quiet while the projection ran. Here, we see how one attempt at visitor engagement interfered with another. 
As the culture of the cinema was enacted, we noticed how a majority of visitors felt as though they should only engage with the short films, and they stopped interacting with everything else. Moreover, on one walking interview, a visitor still trying to engage with the QR codes could not get the app to work because their phone could not scan in the dark. In the end, they gave up and watched the short film, and never went back to try scanning again.

Fourth, a small number of visitors, especially in the Family in Wartime exhibition in IWM London, felt that the objects with the QR codes were relatively uninteresting. They were not inspired by these objects to go to the effort of finding out more about them. This represents a disjuncture between the project teams' expectation of the material affects of objects which they believed to be provocative and those of the museum visitors. This absence of affective association (Light 2014) shaped the (non) engagement.

Fifth, some visitors felt that Scan and Share was an overly complex proposition. Interest was generated but the situation failed to convert into one of full engagement because of the overengineered nature of the attempt at digital engagement by the museum. Participants reported that if they wanted to know more about an object, they would simply Google it. Moreover, if they wanted to capture or share it, they would do so using their smartphone and their own social media account (usually Facebook was named). The need for intervention by the museum was seen as unnecessary. Existing proprietary social media, web and app technologies disrupted the take up of the Scan and Share app.

Finally, participants in the focus groups said that it was unclear from the app's interface what would happen to any comment they made - that is, whether anyone would read it, and who they might be. The focus group participants could not see how the app would provide 
feedback to them about the objects they chose to engage with. For engagement to occur for this group, it was seen as necessary to at least have the possibility to receive feedback from others, and to have some sense of who they were, to complete the social interpretation process. This, combined with the limitations highlighted regarding the complexity of the app and preference for the usage of existing digital and social media, meant that uptake stalled.

\section{Conclusions}

Visiting a museum is a social activity. This is reflected in the way visitors attend with others and in the conversations that take place within the museum. Social interpretation takes place within galleries themselves, albeit in an informal and verbal form, through visitors sharing their thoughts, insights, and expertise about particular objects. We found that this social exchange with friends and family members also continues after the visit, with many participants saying they would tell others about what they had seen. Yet, for most visitors, there appears to have been little incentive to change their existing social interaction and interpretation practices, involving friends and family, to the digital channels established by the museum. Only a small proportion of visitors were excited by the possibility of sharing their thoughts more widely, and hearing from a broader range of other voices in return. This is partly a reflection of the usual distribution of participation and content creation where digital media networks are concerned. For example, most people watch YouTube rather than create content, or even comment on content, the same is the case with Wikipedia ${ }^{4}$. This raises questions about the proper balance between encouraging and facilitating existing behaviours, and seeking to replace or augment them by introducing digital media. Despite all this, the concept itself appeared to have potential. Our research suggests visitors can envisage circumstances in which they might be encouraged to connect with digital media - a

\footnotetext{
${ }^{4}$ See: https://en.wikipedia.org/wiki/Wikipedia:Reader / https://www.youtube.com/yt/press/statistics.html
} 
translation may occur. For example, a switch to sharing, rather than just looking, might occur where the object was one that they were interested in, or where there was an opportunity for discussion with other informed individuals.

In terms of practical implications, the content and physical presence of the comment kiosks clearly acted as engagers in the museum. However, due to visitor interpretations of the role of the kiosks, the resulting dialogue was not necessarily what the museum staff expected. Moreover, the borrowing of social media elements, such as liking, came with negative connotations for some visitors leading the kiosks to be seen as superficial. The importance of the environment of use (or not), and its non-human actors, is further elaborated upon in our analysis of the QR code and App. For instance, unclear signage, disruptions to Wi-Fi, and a lack of users with the right kinds of devices to engage are examples. Furthermore, the role of a dedicated app was seen as a form of barrier even where users had the devices and propensity to engage in interpretation and exchange during their visit. The app was positioned as an unwieldy proposition that clashed with existing social media practice. Museum staff may therefore want to consider how any digital media might be perceived within the museum space and the potential influences of digital culture in society more generally.

Museum practice has embraced the participatory potentials of digital media. To date, an emphasis has been placed on using these associations in a tool-like fashion. Instead of seeing digital media based sets of associations for engagement as subject only to human agency, we have engaged a sociology of translation to highlight the complexity of the non-human as an active participant along with humans. By introducing other actors and examining the success and failures of changes in engagement and connection making through the deployment of a sociology of translation, we add to ANT informed work on museums that highlights 
interactions among museum objects, visitors and staff (Bennet 2005) and museum professionals, objects, the public and information technology (Kéfi and Pallud 2011). We discuss the obvious digital actors such as kiosks and, QR codes and apps, but we also bring to the fore those other materialities which form such networks of relations - lighting, signage and the costs of mobile phone data plans, for instance. In the same way as the objects visitors wish to see at museums have been conceptualized as active producers of meaning (Bagnall 1996; Bagnall 2003), we show how other objects may be implicated. These objects and associations are not neutral and are already encoded in particular ways. For instance, the digital media we discuss in this paper was configured by the project team in order that more complex evaluation data could be captured for analysis; a reporting and service change as much as it was to improve visitor experiences. The meanings, politics and power that digital media actors are coded with, and generate, can play a significant part in the extent to which, and if any, change, or translation, of museum experiences occurs. Digital media and other non-humans were contradictory actors that were seen as helpful and unhelpful in translating different kinds, and unexpected forms of, connections and disconnections amongst visitors, the museum and its objects. Importantly, we need to recognize that this situation is not bound up with the potentially provocative nature of the IWM with its weapons and stories of conflict and loss. Much of IWM's experience is applicable to other forms of museum, and we believe that ANT is one method that is helpful for interrogating these other contexts to unearth other important non-human actors that can mediate the visitor experience in museums.

\section{References}

Akrich, M. (1992). The De-Scription of Technical Objects. Shaping Technology/Building Society: Studies in Sociotechnical Change. W. E. Bijker and J. Law. London, MIT Press: 205-224. 
Light, B., Bagnall, G., Crawford, G. and Gosling, V. The Material Role of Digital Media in Connecting With, Within, and Beyond Museums, Convergence, Pre-publication Version.

Bagnall, G. (1996). Consuming the Past. Consumption Matters: The Production and Experience of Consumption. S. Edgell, K. Hetherington and A. Warde. Oxford, Blackwell: 227-247.

Bagnall, G. (2003). Performance and Performatiity at Heritage Sites. Museum and Society 1(2): 87-103.

Bagnall, G. and A. Rowland (2010). The Imperial War Museum North: A Twenty-First Century Museum? The Future of Memory. J. Kilby and A. Rowland. Oxford, Berghahn.

Bennett, T. (2005). Civic laboratories. Cultural Studies 19(5): 521-547.

Bourdieu, P. (1984). Distinction. London Routledge and Kegan Paul.

Brandon, L. (2007). War, art and the internet: A canadian case study. Convergence: The International Journal of Research into New Media Technologies 13(1): 9-17.

Burgess, J. and J. Green (2009). YouTube: Online Video and Pariciparoty Culture. Cambridge, Polity Press.

Callon, M. (1986). Some Elements of a Sociology of Translation: Domestication of the Scallops and the Fishermen of St Brieuc Bay. Power, Action and Belief: a New Sociology of Knowledge? J. Law. London, Routledge: 196-223.

Crawford, G., V. Gosling, G. Bagnall and B. Light (2014a). Is there an app for that? A case study of the potentials and limitations of the participatory turn and networked publics for classical music audience engagement. Information, Communication \& Society 17(9): 1072-1085.

Crawford, G., V. Gosling, G. Bagnall and B. Light (2014b). An Orchestral Audience: Classical Music and Continued Patterns of Distinction. Cultural Sociology 8(4): 483-500.

Dyson, M. C., M. Andrews and S. Leontopoulou (1995). Multimedia in museums: The need for a descriptive framework. Convergence: The International Journal of Research into New Media Technologies 1(2): 105-124.

Falk, J. (2000). Identity and the Museum Visitor. Walnut Creek, Left Coast Press.

Falk, J. and L. Dierking (2000). Learning from Museums. New York, Rowman-Littlefield.

Fleming, D. (2005). Creative Space. Reshaping Museum Space. London, Routledge

Goulding, C. (2000). The commodification of the past, postmodern pastiche, and the search for authentic experiences at contemporary heritage attractions. European Journal of Marketing 34(7): 835-853.

Hanquinet L. and Savage M. (2012). 'Educative leisure' and the contemporary museum: Belgian case studies', Museum and Society, 20(1): 42-59.

IWM (2015) About Us. http://www.iwm.org.uk/corporate Accessed: 25 August 2015.

Jarrett, K. (2010). YouTube: Online video and participatory culture. Continuum: Journal of Media \& Cultural Studies 24(2): 327-330.

Jenkins, H. (2008). Convergence culture: where old and new media collide. New York, New York University Press.

Kéfi, H. and J. Pallud (2011). The role of technologies in cultural mediation in museums: An actor-network theory view applied in France. Museum Management and Curatorship 26(3): 273-289. 
Kidd, J. (2009) Multimedia Narratives: co-production between museums and their audiences. Cultural Policy, Criticism and Management Research Sic, Sic Retrieved, 21 April 2015 from http://culturalpolicyjournal.files.wordpress.com/2011/05/jenny_kidd.pdf.

Kidd, J. (2011). Enacting engagement online: framing social media use for the museum. Information Technology and People 24(1): 64-77.

Kidd, J. (2014). Museums in the New Mediascape:Transmedia, Participation, Ethics, London: Routledge

Lange, P. G. (2012). Doing it yourself with others. New Media \& Society 14(3): 533-538.

Latour, B. (1992). Where Are the Missing Masses? The Sociology of a Few Mundane Artifacts. In Shaping Technology/Building Society: Studies in Sociotechnical Change. W. E. Bijker and J. Law, Eds. London, MIT Press: 225-258.

Latour, B. (2005). Reassembling the Social: An Introduction to Actor Network Theory. Oxford, Oxford University Press.

Leinhardt, G., K. Crowley and K. Knutson (2011). Learning Conversations in Museums. London, Taylor-Francis.

Light, B. (2014). Disconnecting with Social Networking Sites. Basingstoke, Palgrave Macmillan.

Light, B. and E. Cassidy (2014). Strategies for the suspension and prevention of disconnection: Rendering disconnection as socioecenomic lubricant with Facebook. New Media and Society 16(7): 1169-1184.

Message, K. (2006) The New Museum. Theory, Culture and Society. 23(2-3), 603-606.

Oudshoorn, N. and T. Pinch (2005). How Users and Non-Users Matter. How Users Matter: The Co-Construction of Users and Technology (2005 Paperback edition). N. Oudshoorn and T. Pinch. London, MIT Press: 1-25.

Smith Bautista, S. (2014). Museums in the Digital Age: Changing Meanings of Place, Community and Culture. New York, Rowman and Littlefield.

Srinivasan, R., R. Boast, J. Furner and K. M. Becvar (2009). Digital Museums and Diverse Cultural Knowledges: Moving Past the Traditional Catalog. The Information Society: An International Journal 25(4): 265-278.

Staniszewski, M. A. (2000). Museum as web site, archive as muse: Some notes and ironies of the conventions of display. Convergence: The International Journal of Research into New Media Technologies 6(2): 10-16.

Tolmie, P., S. Benford, C. Greenhalgh, T. Rodden and S. Reeves (2014). Supporting group interactions in museum visiting. CSCW '14. Proceedings of the 17th ACM conference on Computer supported cooperative work \& social computing. New York, ACM: 1049-1059

Vergo, P. (1989). The New Museology. London, Reaktion Books.

Woolgar, S. (1991). Configuring the User: The Case of Usability Trials. A Sociology of Monsters: Essays on Power, Technology and Domination. J. Law. London, Routledge: 6675. 